\title{
GW23-e1798 MYOCARDIAL INFARCT SIZE AND INFARCT TIME PLAY AN IMPORTANT ROLE IN THE MIGRATION OF SCA-1+ CARDIAC STEM CELL
}

doi:10.1136/heartjnl-2012-302920a.256

Yongshun Wang, Bo Yu. Department of Cardiology, Second Affiliated Hospital of Harbin Medical University Heilongjiang Province, China

Objectives After myocardial infarction, the limited ability of regeneration of myocardial tissue can barely repair the extensive necrosis of myocardial cells. For further revealed the mechanism of myocardical restoration, this study detected the migration and the quantity changes of Sca- $1^{+}$cardic stem cell after myocardical infarction. Methods Wister Rats were anesthetised and left anterior descending (LAD) coronary artery was ligated for 1 week, 2 weeks and 4 weeks. Then randomly divided into Control group (CG) and Infarction 1 week group (IG1), Infarction 2 weeks group (IG2) and Infarction 4 weeks group (IG4). Followed, the rats were executed, and the myocardial tissue of rats in each group was frozen and paraffin-embedded. After that, HE staining was to assess tissue damage, Collagen staining (Masson staining) was to assess infarct size, the migration and quantity changes of Sca- 1 positive cell were assessed by Immunofluorescence and immunohistochemistry.

Results Immunofluorescence and immunohistochemistry showed that (1) Sca- $1^{+}$cardiac stem cells in the infarcted zone express greater number than the infarct border zone; (2) After myocardical infarction, cardic stem cell has migrated to the infarct zone and perivascular; (3) Migration of cardiac stem cells were proportional to the infarct size; (4) Sca- $1^{+}$cardiac stem cells at IG4 expressed larger number than IG1or IG2.

Conclusions After myocardical infarction, cardic stem cell has migrated to the infarct zone and perivascular, which were decided by the proportional of infarct size and infarct time. 